\title{
Recognize both Objective and Subjective Dimensions of Recovery of Severe Mental Illness
}

\author{
Feng Zhang ${ }^{1}$, Man C.M. Tsui ${ }^{2} \& \mathrm{Da} \mathrm{Li}^{1}$ \\ ${ }^{1}$ Wuxi Mental Health Center, Wuxi Tongren International Rehabilitation Hospital, China \\ ${ }^{2}$ Hong Kong Institute of Technology, Hong Kong \\ Correspondence: Da Li, Wuxi Mental Health Center, Wuxi Tongren International Rehabilitation Hospital, \\ Nanjing Medical University, China. Tel: 852-9324-4185. E-mail: 13358119052@163.com
}

\author{
Received: January 18, 2016 \\ Accepted: January 20, 2016 \\ Online Published: February 29, 2016 \\ doi:10.20849/ajsss.v1i1.23 \\ URL: http://dx.doi.org/10.20849/ajsss.v1i1.23
}

Fostering psychiatric rehabilitation philosophy and practices for individuals with severe mental illness (SMI) in the mainland China is of urgent needs but various challenges exist. Psychiatric rehabilitation targets specifically at those with SMI which utilizes pharmacological treatment for controlling the signs and symptoms, and psychosocial interventions for restoring psychological and social functioning including interpersonal relationships, work, leisure and quality of life (Meehan et al., 2007). The nature of its outcomes can be both objective and subjective. It can be objective indicators by the measures of symptom remission and the level of social functioning, and also subjective ones such as feeling of hope, discovery of meaning of life, and taking control and personal responsibilities (King et al., 2007). Equal share of the recognition of both dimensions and hence the corresponding strategies and interventions has been advocated (Deegan, 2003). Nevertheless, the implementation of psychiatric rehabilitation in the mainland China has been difficult. The multiple bio-psycho-social dimensions of interventions necessitate the input from various professionals including psychiatrists, psychiatric nurses, occupational therapists, social workers and psychologists. Unfortunately, this multi-disciplinary team is not available in the mainland as the availability of the latter three remains very limited. While psychiatrists and psychiatric nurses are specialized in pharmacotherapy, they may not have clear concepts of psychosocial rehabilitation and hence the directions of practices ( $\mathrm{Li}$ et al., 2014) as these are not the expertise of them but the occupational therapists, social workers and psychologists. The development of psychosocial interventions such as supported employment, community living skills training and social skills training is therefore undermined. It in turn hinders the optimization of the recovery process and outcomes. It is not surprising to find that remission of positive signs and symptoms seems to remain the only indicator of objective recovery. In fact, the effectiveness of the implemented strategies and interventions on the other hand can reinforce the recognition of the recovery dimensions. In response to the pressing needs of developing psychosocial rehabilitation in the mainland, there have been a number of psychosocial interventions including a pilot program on Integrated Supported Employment (ISE; Tsang et al., 2009) which integrates Individual Placement and Support (Drake \& Becker, 1996) and Work-related Social Skills Training (Tsang \& Pearson, 2001) for people with schizophrenia. The positive outcomes including higher employment rate and longer job tenure shown in a randomized controlled trial ( $\mathrm{Li}$ et al., 2013) suggested that this psychosocial rehabilitation program could be applicable to help the individuals with schizophrenia there to enhance their social functioning by gaining employment and thus community reintegration. The employment rate and job tenure can hence serve as another objective indicator of recovery. Concerning the subjective dimensions, it is hard for persons with SMI to recover if they cannot be guided to generate personal meaning and understanding of their life (Glover, 2007). The ISE also plays a crucial role in it by facilitating the rehabilitants to construct and regularly review their own recovery process. This further supports the need to expand and supplement the scope of recovery by incorporating subjective dimensions into the conventional objective dimensions so as to facilitate the recovery process and outcomes.

In short, the development of strategies and interventions of psychiatric rehabilitation cannot be made possible without equal share of the recognition of both objective and subjective dimensions of recovery for individuals with SMI. 


\section{References}

Deegan, G. (2003). Discovering recovery. Psychiatric Rehabilitation Journal, 28, 368-376.

Drake, R. E., \& Becker, D. R. (1996). The individual placement and support model of supported employment. Psychiatric Services, 47, 473 -475.

Glover, H. (2007). Lived experience perspectives. In R. King, C. Lloyd, \& T. Meehan (Eds.), Handbook of psychosocial rehabilitation. UK: Blackwell Publishing Ltd.

King, R., \& Lloyd, C. (2007). Family psychoeducation. In R. King, C. Lloyd, \& T. Meehan (Eds.), Handbook of psychosocial rehabilitation. UK: Blackwell Publishing Ltd.

Li, D., Tsui, M. C. M., \& Yuan, G. (2014). China's new Mental Health Law needs to tackle manpower imbalance of professionals in schizophrenia psychosocial rehabilitation. International Journal of Social Psychiatry, 60, 410-411.

Li, D., Yuan, G., Xu, Z., Zeng, Y., \& Zhang, G. (2013). Effects of supported employment on vocational rehabilitation for schizophrenia patients: A randomized controlled study. Chinese Journal of Behavioral Medicine and Brain Science, 2, 8-10.

Meehan, T. (2007). Major mental illness and its impact. In R. King, C. Lloyd, \& T. Meehan (Eds.), Handbook of psychosocial rehabilitation. UK: Blackwell Publishing Ltd.

Tsang, H. W. H., Chan, A., Wong, A., \& Liberman, R. P. (2009). Vocational outcomes of an integrated supported employment program for individuals with persistent and severe mental illness. Journal of Behavior Therapy and Experimental Psychiatry, 40(2), 292-305.

Tsang, H. W. H., \& Pearson, V. (2001). Work-related social skills training for people with schizophrenia in Hong Kong. Schizophrenia Bulletin, 27(1), 139-148.

\section{Copyrights}

Copyright for this article is retained by the author(s), with first publication rights granted to the journal.

This is an open-access article distributed under the terms and conditions of the Creative Commons Attribution license (http://creativecommons.org/licenses/by/3.0/). 